\title{
Age and Gender Differences in the Sources of Self-Evaluation Valued by Adult Athletes
}

\author{
Jane P. Sheldon ${ }^{1}$
}

\begin{abstract}
Researchers have demonstrated that competency judgments can vary depending on the source of self-evaluation used. This study investigated age and gender differences in 459 adult tennis players' importance ratings for ten different competence information sources. As predicted, younger adults were more likely than older adults to value temporal comparisons, both pastto-present (i.e., personal improvement) and present-to-future (i.e., comparisons with future selves). Younger adults were more likely to value feedback from family for self-evaluation. Older adults were slightly more likely to rate comparisons with agemates as important. Women more than men valued feedback from tennis others, effort, and liking for the sport. The findings are consistent with theoretical models and point to new areas of investigation.
\end{abstract}

KEY WORDS: self-evaluation; perceived competence; adulthood; sports; temporal comparison.

\section{INTRODUCTION}

Although several different motives may underlie individuals' use of self-evaluation (e.g., selfenhancement, self-verification), one reason for the use of self-evaluation is that individuals have a need to assess their personal competence (Pomerantz, Saxon, \& Kenney, 2001). Assessments of self-competence help people make effective plans and decisions about their future behavior (Markus, Cross, \& Wurf, 1990). Researchers (Frey \& Ruble, 1990; Stipek \& Mac Iver, 1989) have theorized and demonstrated that competency judgments can vary depending on the source of self-evaluation used; therefore, knowledge about sources of self-assessment is a necessary component in understanding individuals' self-perceptions of competence.

Self-evaluation research in the cognitive and social domains has often differentiated between internal and external sources of evaluation. Internal sources relate to the individual's physical and psy-

\footnotetext{
$\overline{{ }^{1} \text { To whom }}$ correspondence should be addressed at Department of Behavioral Sciences, University of Michigan - Dearborn, Dearborn, Michigan 48128; e-mail: jsheldon@umd.umich.edu.
}

chological processes, such as amount of effort exerted, affect, ease in learning, and skill improvement. Albert (1977) suggested that personal improvement over time is a particularly important source of competence information and labeled such past-to-present comparisons as a form of "temporal comparison." External sources used for self-assessment are social sources such as comparisons with others (i.e., social comparison; Festinger, 1954) and feedback from others. In addition, outcomes and objective measures (e.g., score on a test, awards won) can be used for self-assessment (Stipek \& Mac Iver, 1989). Individuals likely use several different sources of competence information, but may prefer certain ones over others.

Albert's temporal comparison theory focused on the importance of past-to-present comparisons for self-evaluation (Albert, 1977), yet he acknowledged briefly that another sort of temporal comparisonfrom the present to the future-could also be used for self-assessment. However, only a few studies have included measures pertaining to comparisons with future selves (Horn, Glenn, \& Wentzell, 1993; Sedikides \& Skowronski, 1995; Wayment \& Campbell, 2000). 


\section{Age Differences in Self-Evaluation}

Research in both the cognitive (Ruble, Boggiano, Feldman, \& Loebl, 1980; Stipek \& Mac Iver, 1989) and athletic (Horn \& Hasbrook, 1986, 1987; Weiss, Ebbeck, \& Horn, 1997) domains has shown that the type of self-assessment information individuals value can vary with age; however, most of these studies have been conducted with children and adolescents rather than adults. Although Ebbeck (1990) and Herrald and Lucker (1995) investigated the self-evaluation sources valued by adults in exercise and sport settings, they did not include age comparisons, likely due to the small range of ages in the college student samples.

Theoretical research regarding age differences in adults' use of self-evaluation information has generally focused on only social comparison and temporal comparison. Albert (1977) proposed in his temporal comparison theory that during times of decline temporal comparisons will be less emphasized and instead social comparisons will be preferred. Expanding on Albert's theory (Albert, 1977), Frey and Ruble (1990; Ruble \& Frey, 1991) suggested that in physical activities, where there is inevitable decline with age, older adults will be more likely than younger adults to rely on a specific sort of social comparisoncomparisons with same-age others-rather than on temporal comparison. Their study of self-evaluation in 237 long-distance runners between the ages of 20 and 77 years (Frey \& Ruble, 1990) confirmed their hypothesis.

Based on theory and findings by Albert (1977) and Frey and Ruble (1990; Ruble \& Frey, 1991), I hypothesize that older adult athletes will be more likely than younger adult athletes to rate as important social comparison, especially comparisons with sameage others, and will be less likely to value temporal comparisons.

\section{Gender Differences in Self-Evaluation}

Gender differences in the importance assigned to self-evaluation information have been investigated in both the cognitive and athletic domains and with both children and adults (e.g., Barber, 1998; Ebbeck, 1990; Horn \& Hasbrook, 1986; Williams, 1994). Studies investigating the importance assigned to objective measures as a source of competence information have revealed no significant gender effects (Barber, 1998; Horn \& Hasbrook, 1986).

\section{External Sources}

Research concerning gender differences in social comparison has produced mixed results. Studies of adults in the cognitive domain (Schwalbe \& Staples, 1991; Sedikides \& Skowronski, 1995) and youth in the athletic domain (Williams, 1994) have shown that males are more likely than females to value social comparison. Other research, involving adults (Barber, 1998; Ebbeck, 1990) and youth (Horn \& Hasbrook, 1986) in the athletic domain, has shown no gender difference for this form of self-assessment.

Investigations of gender differences in feedback from others have also shown inconsistent findings. Research concerning adults' self-evaluation in nonsport settings (Alagna, 1982; Roberts \& Nolen-Hoeksema, 1994) has demonstrated that women more than men value feedback from others to evaluate their competence. Ebbeck's research (Ebbeck, 1990), however, found the opposite. In the athletic domain, studies of children (Horn \& Hasbrook, 1986; Williams, 1994) and adults (Barber, 1998) have found no gender difference for feedback from others.

\section{Internal Sources}

Although Horn and Hasbrook (1986) found in their study of youth athletes that boys and girls did not differ in the importance they assigned to internal sources, several studies have shown that female adults in both the cognitive (Schwalbe \& Staples, 1991; Sedikides \& Skowronski, 1995) and athletic/exercise domains (Barber, 1998; Ebbeck, 1990; Herrald \& Lucker, 1995) are more likely than male adults to value internal sources of self-evaluation. Therefore, I hypothesize that adult female tennis players will be more likely than male tennis players to value internal self-assessment sources.

\section{METHOD}

\section{Participants}

Four hundred and sixty-six (80\%) of the 584 surveys were completed and returned. The participants ( 323 women, 143 men) were involved in United States Tennis Association (USTA) USA Leagues at 15 different tennis facilities. Ninety percent of the participants were White, 4\% were African American, $3 \%$ were Asian American, and 2\% were Hispanic. 
One percent of the sample did not indicate their race/ethnicity. Players' ages ranged from 19 to 74 years $(M=44)$.

For statistical analyses participants were divided into three age groups based on conceptually relevant categories. Seven participants did not report their age; therefore, their responses could not be used in data analyses. The Younger Age Group (12 men, 24 women) consisted of players 19 through 30 years of age. Players whose ages were from 31 to 49 years comprised the Middle Age Group (78 men, 209 women). The Older Age Group (49 men, 87 women) contained players 50 years of age and older. These category divisions correspond to both milestone ages and average ages at which significant physical changes occur, such as declines in cardiovascular performance, vision, and strength (Hayflick, 1996; Kosnik, Winslow, Kline, Rasinski, \& Sekuler, 1988; Schultz \& Curnow, 1988; Sinclair, 1989).

\section{Measures}

A modified version of Horn and Weiss's Physical (or Sport) Competence Information Scale (PCIS or SCIS) was used to assess what sources of information individuals rate as important when evaluating their own tennis competence (Horn and Weiss, 1991). The instructions asked players to rate "how important each item is for helping you determine how good you are at tennis." Participants rated the personal importance of each competence information source on a 5-point scale ranging from not at all important (1) to extremely important (5). Each competence information source was assessed using three items. The 12 self-evaluation sources were game outcome, degree of skill improvement, feedback from coach, pregame nervousness or worry, ease in learning skills, feedback from parents, feedback from teammates, performance in games, amount of effort exerted, personal attraction to sport, social comparison, and feedback from spectators. Although researchers (Horn \& Hasbrook, 1986; Horn \& Weiss, 1991) have found spectator feedback to be a weak factor for youth athletes, spectator feedback items were included in this study of adult athletes. Also for the purpose of this study, the wording of items related to feedback from parents was changed to be feedback from family members. Additionally, one item ("compare myself to how I used to be") was added to the degree of skill improvement factor because the wording of this temporal comparison item much more directly assessed evaluations related to past-to-present comparisons.

Following Albert's theory (Albert, 1977), four items related to one's sense of future selves were added to the self-evaluation measure. These items were: "compare myself to how I think I should be"; "compare myself to how I want to be"; "whether I perform as well as I expect to"; and "compare myself to how I think I could possibly be." Ratings involved the same 5-point scale.

Frey and Ruble's theoretical perspective (Frey \& Ruble, 1990) predicts that a specific form of social comparison-comparisons with same-age individuals-will differ between older and younger adults; therefore, players also rated the importance on a 5-point scale of "how I compare to other players my age."

\section{Procedure}

Players who volunteered to participate were provided with a survey, consent form, stamped and addressed envelopes for mailing, and a can of tennis balls as a thank-you gift. They could take the survey home to fill out at a more convenient time. Participants did not include their names on the surveys in order to insure anonymity.

\section{RESULTS}

\section{Factor Analysis}

In order to determine the factor structure for this sample of adults, the self-evaluation data (excluding the one-item measure of comparisons with same-age players) were subjected to a principal components exploratory factor analysis using a varimax rotation. Items having a factor weight of at least .40 were deemed as part of a factor. Nine factors resulted, each having an eigenvalue greater than 1 , which corresponded to the information gained by examining the eigenvalue scree plot. These nine factors explained $67.45 \%$ of the variance.

Scales were created by computing the unweighted mean of the scores loading highly on each factor. An item related to feedback from teammates loaded on more than one factor, so it was not included in the creation of scales. The first factor $(\lambda=4.66)$, Investment in the Sport, consisted of seven items pertaining to liking the sport, working hard, and 
getting psyched up before matches. The second factor $(\lambda=3.90)$ consisted of five items related to feedback from coaches and teammates; therefore, this factor was labeled Feedback from Tennis Others. The seven items in factor $3(\lambda=3.36)$ concerned spectator feedback, scores/statistics, one's position in the line-up, and ease in learning. This factor was labeled Objective Measures because of the focus on numerical information and feedback from those with whom the participants did not have a close personal relationship (i.e., spectators). Performing well in matches and attending to one's win/loss record were the themes in factor $4(\lambda=3.21)$; therefore, this 4 -item factor was labeled Match Play. Factor $5(\lambda=3.00)$ contained three items pertaining to Feedback from Family. Four items concerning comparisons with how one could be, should be, wants to be, and expects to be were contained in factor $6(\lambda=2.76)$, Future Selves. Factor $7(\lambda=2.29)$, Social Comparison, contained three items concerning comparing oneself to teammates, other players, and opponents. Factor $8(\lambda=2.25)$ consisted of three items related to skill improvement and therefore was labeled Personal Improvement. Four items related to anxiety and ease in learning loaded on factor $9(\lambda=2.22)$, Tension. All internal consistencies (Cronbach, 1951) were equal to or exceeded .70, which is considered to be the minimum acceptable value (Nunnally, 1978). Interfactor correlations equal to or greater than .70 indicate the presence of multicollinearity (Pedhazur, 1982); however, all interfactor correlations for this sample were below .57.

\section{Age and Gender Comparisons}

In order to test whether there are age and gender differences in the sources of self-evaluation adult athletes value, a 3 (Age Group) $\times 2$ (Gender) MANCOVA was performed. The nine scales resulting from the exploratory factor analysis, along with the oneitem measure of same-age comparisons, served as the dependent variables. Ruble and Frey's model (Ruble \& Frey, 1991) and Ruble and Flett's results (Ruble \& Flett, 1988) indicate that skill level may relate to the sources of self-evaluation information individuals utilize; therefore, skill level was entered as a covariate in the MANCOVA. A relatively objective rating of tennis skill is players' USTA rating, which was assessed or verified for each player in the sample by a trained professional. Ratings are based on tennis abilities such as shot placement, consistency, power, use of spins, and win/loss records.
After the effect of skill level was controlled for, an age main effect was found for sources of selfevaluation, Wilks's Lambda $=.91, F(20,880)=2.17$, $p=.002, \eta^{2}=.05$, power $=.99$. Follow-up ANOVAs showed significant age differences in the importance assigned to Feedback from Family $[F(2,449)=4.40$, $p=.01]$, Personal Improvement $[F(2,449)=4.10$, $p=.02]$, and Future Selves $[F(2,449)=2.96, p=$ .05]. An ANOVA also showed an age difference (trend level) for Comparisons with Same-Age Players, $F(2,449)=2.57, p=.08$. Fisher least significant difference tests indicated that players in the Younger Age Group were more likely than those in the Middle Age and Older Age Groups to value Feedback from Family and Personal Improvement as self-evaluation sources. Players in the Younger Age Group were also more likely than those in the Older Age Group to rate Future Selves as an important self-assessment tool. In terms of Comparisons with Same-Age Players, adults in the Older Age Group were slightly more likely than adults in the Middle Age Group to value comparisons with agemates.

The MANCOVA also showed a main effect for gender, Wilks's Lambda $=.94, F(10,440)=2.90$, $p=.002, \eta^{2}=.06$, power $=.98$. Univariate analyses demonstrated significant gender differences in the importance assigned to Feedback from Tennis Others $[F(1,449)=9.45, p=.002]$ and Investment in the Sport $[F(1,449)=4.42, p=.04]$. Women were more likely than men to value both these sources of competence information. No significant age by gender interactions occurred.

\section{DISCUSSION}

Frey and Ruble's model of self-evaluation sources is the first to address specifically the developmental aspect of competence self-assessment (Frey \& Ruble, 1990). The findings of this study are consistent with Frey and Ruble's contention that selfevaluative needs and motives change over time and that age should be accounted for when individuals' self-evaluation processes are assessed. As predicted, younger adults were more likely than older adults to value temporal comparisons, both past-to-present (i.e., improvement) and present-to-future (i.e., comparisons with future selves). However, it is important to acknowledge that the effect sizes were very small, which indicates that other variables play a role in competence self-assessment. Indeed, the covariate of skill level accounted for more of the variance 
$(12 \%)$ than both age and gender combined. Research has shown that other variables, such as motivation orientations (Williams, 1994), perceived competence (Horn \& Hasbrook, 1987), and perceived control (Horn \& Hasbrook, 1987), also play a role in the importance assigned to different sources of competence information.

Of particular interest are the age effects for social comparison. Consistent with the hypothesis, there was a trend showing that older adults were more likely than the middle age adults to value comparisons with agemates for evaluating their tennis competence. However, there was no age difference in the importance assigned to other forms of social comparison, such as comparisons with teammates and opponents. The former result is in accordance with theory and research by Frey and Ruble (1990). The combination of these two findings points to the need for measures of social comparison to take into account the age of comparison others. In athletic activities that divide participants into age groups for competition, most social comparisons will be with same-age others because both teammates and opponents (the most likely targets of social comparison) will necessarily be of the same age. However, many athletic activities do not use age groupings; therefore, measures of social comparison for athletes in such activities may need to delineate more clearly the ages of comparison others.

Additionally, the results show that temporal comparisons with future selves serve as a form of self-evaluation information. Unlike some sources of competence self-assessment, future selves are information sources that individuals can control and change through cognitive behavioral techniques. Future research needs to include comparisons with future selves in measures of self-assessment sources in order to discover if this study's findings are generalizable to other athletic activities and age groups, as well as to different domains.

Family feedback was more important for the younger age group than for the other two age groups. Perhaps individuals in their 20s still rely on parental approval and feedback; whereas older adults, who are generally more mature and independent, rely much less on parental support. For older adults any feedback they receive from family members, such as their spouse and children, may be of little use in their competence evaluations because feedback from these family members is not perceived as objective, informed, or tied with a need for approval.

Women have been shown to be more likely than men to value feedback from others for self-evaluation
(Alagna, 1982; Roberts \& Nolen-Hoeksema, 1989, 1994). This study also found this result; however, it is important to note that the findings did not show a gender difference in the importance assigned to one source of feedback-feedback from family members. Thus, the feedback women were more likely than men to value came from individuals whose knowledge and experience in the sport of tennis were likely equal to or greater than their own, rather than from family members, who may not have much tennis knowledge. These findings are consistent with Roberts' review of the literature concerning gender differences in the importance given to others' evaluations (Roberts, 1991). Roberts discussed research supporting the idea that women may be more likely than men to have an open, flexible, noncompetitive attitude when gaining evaluative information about their abilities and may view such situations as opportunities in which to learn about their skills rather than as challenges to their self-confidence. Because family members' feedback is likely seen as more subjective and less knowledgeable than feedback from tennis others, women may not differ from men in the importance assigned to this competence information source because it is not seen as instructive.

This study's results partially supported the hypothesis that female athletes are more likely than male athletes to value internal sources of selfevaluation. A gender difference was found for Investment in the Sport. The Investment in the Sport factor included items related to liking the sport and exerting effort; thus, this finding is in accordance with other research (Ebbeck, 1990; Sedikides \& Skowronski, 1995). No gender differences were found for Personal Improvement or Future Selves. Albert (1977) predicted that when individuals are experiencing rapid change in their abilities and when they want to predict future performance, they will use temporal comparisons as a form of self-assessment. Therefore, the lack of a gender difference for either form of temporal comparison (i.e., Personal Improvement, Future Selves) is not surprising, in that both male and female tennis players experience rapid change as they learn new skills and, presumably, athletes of both genders hope to know how well they will play in the future.

Many studies (Barber, 1998; Ebbeck, 1990; Horn \& Hasbrook, 1986; Ruble et al., 1980) have found no gender difference in the importance assigned to social comparison, just as this study did. As recommended by Horn and Amorose (1998), future psychometric work is needed in order to develop measures 
that accurately assess the specific types of others (e.g., "near peers" or "extended peers") important for comparison.

\section{Limitations and Future Directions}

It is unclear how generalizable the results from a tennis player sample are to other athletic activities. For example, sports in which athletes compete against a clock (e.g., running, swimming) may bring pastto-present comparisons and comparisons with absolute standards to the forefront. Future research will help discern the similarities and differences between sports in terms of the self-assessment sources athletes value.

Although it is wise to be cautious in generalizing from one study (especially when the effect sizes are small), the implications for applied work stemming from this study's findings are that instructional and competitive programs for adult athletes may need to be structured differently depending on the age and gender of the participants. By being cognizant of potential group (and individual) variations in the importance assigned to different self-assessment sources, instructors can develop programs that foster feelings of competence, thus promoting adults' participation in activities that enhance physical and psychological health.

\section{ACKNOWLEDGMENT}

This research was funded by a grant from the United States Tennis Association.

\section{REFERENCES}

Alagna, S. W. (1982). Sex role identity, peer evaluation of competition, and the responses of women and men in a competitive situation. Journal of Personality and Social Psychology, 43, 546-554.

Albert, S. (1977). Temporal comparison theory. Psychological Review, 84, 485-503.

Barber, H. (1998). Examining gender differences in sources and levels of perceived competence in interscholastic coaches. The Sport Psychologist, 12, 237-252.

Cronbach, L. (1951). Coefficient alpha and the internal structure of tests. Psychometrika, 16, 297-334.

Ebbeck, V. (1990). Sources of performance information in the exercise setting. Journal of Sport and Exercise Psychology, 12, $56-65$.

Festinger, L. A. (1954). A theory of social comparison process. Human Relations, 7, 117-140.

Frey, K. S., \& Ruble, D. N. (1990). Strategies for comparative evaluation: Maintaining a sense of competence across the life span. In R. J. Sternberg \& J. Kolligan Jr. (Eds.), Competence considered (pp. 167-189). New Haven, CT: Yale University Press.
Hayflick, L. (1996). How and why we age. New York: Ballantine Books.

Herrald, M. M., \& Lucker, G. W. (1995). Ethnic and gender variations in the sources of information used to evaluate performance in the exercise setting. Journal of Applied Social Psychology, 25, 2180-2191.

Horn, T. S., \& Amorose, A. J. (1998). Sources of competence information. In J. L. Duda (Ed.), Advances in sport and exercise psychology measurement. Morgantown, WV: Fitness Information Technology.

Horn, T. S., Glenn, S. D., \& Wentzell, A. B. (1993). Sources of information underlying personal ability judgments in high school athletes. Pediatric Exercise Science, 5, 263-274.

Horn, T. S., \& Hasbrook, C. (1986). Informational components influencing children's perceptions of their physical competence. In M. R. Weiss \& D. Gould (Eds.), Sport for children and youths. Champaign, IL: Human Kinetics.

Horn, T. S., \& Hasbrook, C. (1987). Psychological characteristics and the criteria children use for self-evaluation. Journal of Sport Psychology, 9, 208-221.

Horn, T. S., \& Weiss, M. R. (1991). A developmental analysis of children's self-ability judgments in the physical domain. Pediatric Exercise Science, 3, 310-326.

Kosnik, W., Winslow, L., Kline, D., Rasinski, K., \& Sekuler, R. (1988). Visual changes in daily life. Journal of Gerontology, $5,227-235$

Markus, H., Cross, S., \& Wurf, E. (1990). The role of the self-system in competence. In R. J. Sternberg \& J. Kolligan Jr. (Eds.), Competence considered (pp. 167-189). New Haven, CT: Yale University Press.

Nunnally, J. C. (1978). Psychometric theory (2nd ed.). New York: McGraw-Hill.

Pedhazur, E. J. (1982). Multiple regression in behavioral research. New York: Holt, Rinehart \& Winston.

Pomerantz, E. M., Saxon, J. L., \& Kenney, G. A. (2001). Selfevaluation: The development of sex differences. In G. B. Moskowitz (Ed.), Cognitive social psychology: The Princeton symposium on the legacy and future of social cognition (pp. 5973). Mahwah, NJ: Erlbaum.

Roberts, T. (1991). Gender and the influence of evaluations on selfassessments in achievement settings. Psychological Bulletin, 109, 297-308

Roberts, T., \& Nolen-Hoeksema, S. (1994). Gender comparisons in responsiveness to others' evaluations in achievement settings. Psychology of Women Quarterly, 18, 221240 .

Ruble, D. N., Boggiano, A. K., Feldman, N. S., \& Loebl, J. H. (1980). Developmental analysis of the role of social comparison in selfevaluation. Developmental Psychology, 16, 105-115.

Ruble, D. N., \& Flett, G. L. (1988). Conflicting goals in self-evaluative information seeking: Developmental and ability level differences. Child Development, 59, 97106.

Ruble, D. N., \& Frey, K. S. (1991). Changing patterns of comparative behavior as skills are acquired: A functional model of self-evaluation. In J. Suls (Ed.), Social comparison: Contemporary theory and research (pp. 79-113). Hillsdale, NJ: Erlbaum.

Schultz, R., \& Curnow, C. (1988). Peak performance and age among super athletes: Track and field, swimming, baseball, tennis, and golf. Journal of Gerontology, 43, 113-120.

Schwalbe, M. L., \& Staples, C. L. (1991). Gender differences in sources of self-esteem. Social Psychology Quarterly, 54, 158168.

Sedikides, C., \& Skowronski, J. J. (1995). On the sources of selfknowledge: The perceived primacy of self-reflection. Journal of Social and Clinical Psychology, 14, 144-270.

Sinclair, D. (1989). Human growth after birth. New York: Oxford. 
Stipek, D., \& Mac Iver, D. (1989). Developmental change in children's assessment of intellectual competence. Child Development, 60, 521-538.

Wayment, H. A., \& Campbell, S. (2000). How are we doing? The impact of motives and information use on the evaluation of romantic relationships. Journal of Social and Personal Relationships, 17, 31-52.
Weiss, M. R., Ebbeck, V., \& Horn, T. S. (1997). Children's selfperceptions and sources of physical competence information: A cluster analysis. Journal of Sport and Exercise Psychology, $19,52-70$.

Williams, L. (1994). Goal orientations and athletes' preferences for competence information sources. Journal of Sport and Exercise Psychology, 16, 416-430. 